\title{
Special Considerations of the Financial Investment in Russia
}

\author{
Roman V. Kolupaev ${ }^{1}$, Lyubov I. Rogacheva ${ }^{1}$, Anna V. Moskalenko ${ }^{1}$, Irina V. Ulrikh ${ }^{1} \&$ Tatyana A. Mikhailova $^{1}$ \\ ${ }^{1}$ Russian State Social University, Moscow, Russia \\ Correspondence: Roman V. Kolupaev, Russian State Social University, Wilhelm Pieck st. 4, building 1, Moscow, \\ 129226, Russia.
}

Received: February 8, 2015 Accepted: February 18, 2015 Online Published: March 16, 2015

doi:10.5539/ass.v11n7p297 URL: http://dx.doi.org/10.5539/ass.v11n7p297

\begin{abstract}
The article describes special considerations of the financial investment in Russia. Based on the results of the research conducted, it is noted that diversification, rational attitude to risk, forecasting and insurance provide all together the best solutions for any kind of investment in the Russian Federation. Investing in Russia is always subject to different risks. Thus, solutions to possible problems should be reflected in the so-called risk list. This document should be developed directly before investing and should include all risks most common to a certain scope of investment. Also, it is necessary to assess potential losses and provide ways to minimize them.
\end{abstract}

Keywords: investments, investors, finance, capital, management, market, income

\section{Introduction}

Investing in Russia has a variety of differences and peculiarities that require a special study of the issue. New financial markets in developing countries and transition economies have some special features. At present, there are more opportunities for them to attract foreign capital, use the accumulated information and experience of other countries, as compared with the passed time of financial markets development in advanced nations. Therefore, the processes in emerging markets are characterized by sharp fluctuations and a more rapid pace of development.

The economic situation in Russia in the foreseeable future will be affected by structural bottlenecks and lower oil prices". All of this will be further exacerbated by geopolitical tensions, associated primarily with the situation around Ukraine.

Inflation in annual expression reached 15.6 percent, exceeding the key interest rate of the Bank of Russia. On it informs "Interfax" with reference to the data of Rosstat. 9 February 2015 the economic development Minister Alexei Ulyukayev forecast that in March, inflation will peak in the 15-17 percent. According to the Minister, in the following months it will be reduced. According to the updated forecast of the Ministry of economic development, inflation in 2015 will amount to 12 percent.

Amid sanctions against Russia's investment climate has deteriorated very much. Fewer and fewer companies are willing to invest in the Russian projects or just can't do it. Russian companies also face difficulties, especially in terms of attracting funding for projects. In this situation, the government should smooth things out, to try to increase the attractiveness of any investment.

The financial crisis in Russia revealed the need to build such a structure of financial instruments, which would provide the reorientation of financial flows to service the needs of end borrowers, improving influx of free resources and their investment into sound economic projects. Circumstances, where a loss of competitiveness of government securities creates real opportunities for the development of other financial instruments, form the prerequisites for corporate issuers to enter to the Russian financial market.

The role of financial market has been also reassessed. It is no longer considered as an engine for further development of the economy as a whole. Moreover, it becomes increasingly clear that it is the development of the real sector of the economy and the transition of producers to the predominant use of the monetary forms of payment that must become the prelude to an effective expansion of the operations of financial and credit institutions with the real sector and the subsequent buoyancy in the financial markets. 


\section{Methodology}

In order to obtain and use the relevant information, in this article author used the analysis technique of the technical, economic and scientific literature, comparative analysis of statistical data, and other methods.

\section{Main Part}

The peculiarities of the Russian financial market include the importance of its social component. Russian citizens require a variety of ways to invest their savings and ensuring personal financial security. Therefore, when developing the policy in relation to the securities market, the state is not only based on the needs of the economy and the availability of investments, but also focuses on the needs of the population in general. The acuteness of social issues in the development of the capital market is due to the fact that Russian citizens have lost much of their savings as a result of inflation, as well as the activities of financial pyramids, which have deceived trustful investors.

Considering in general the investments in Russia, we should note that they can be grouped like all other investments:

- Depending on the object types: financial investments (financial instruments, shares of Russian companies and businesses, bonds and similar securities), investments into Russian real estate, venture capital investments, real investments, and so on;

- Depending on the investment terms: short-range investments, medium-term investments and long-dated investments;

- Depending on the patterns of ownership: public, private, foreign, and joint (with different sources of funds).

At present, many successful companies are rapidly growing, expanding, or are on the verge of entering the external world market.

\section{Results}

In fact, presently legal and natural persons, having accumulated some capital, prefer not to leave it in the bank, but invest in a variety of financial and real tools to gain a fixed return or incidental profit. These is positive trend for both investors and objects of their investments since enterprises, business projects and start-ups receive the necessary funds and at the same time the opportunity to develop ideas and expand their production and spheres of commercial influence. Investors, in turn, have all chances to get the planned revenue at sufficiently low risk (Pishchulin \& Rogachev, 2010; Kolupaev, 2014).

Great interest in investing into the Russian economy is shown by foreign investors. With convenient geographic location, resources and sufficiently well-developed and stable economy, today Russia is an attractive target for foreign investments. Both domestic and foreign investors pay great attention to opportunities of financial investments in Russia, since it is clear to everyone that in the future such investments will bring a decent income.

Historically, the most attention of investors is attracted by the companies, operating in the gas, oil and petrochemical field. Mining and metal processing are not deprived of attention as well. However, gradually the scope of investors' interests changes and they are increasingly paying attention to companies and start-ups, operating in the field of information technology, construction and retail trade (Maloletko et al., 2014).

Among the investors, there are quite a lot of representatives from western and eastern countries, venture capital funds, companies and individuals. Gradually the significance and prospects of investments become clear to domestic private investors and even representatives of the state, therefore every year the amount of investments in many economy sectors is growing steadily.

However, the statistics for the last time indicates some slowing and reducing the amount of foreign investments into Russian projects (Kolupaev, 2014; Ulrich, 2011).

Quite different trends are observed in the Russian investment market that indicates an increase in the attention of domestic investors to their own national investment market. At the same time an increase in the amount of domestic investments shows the confidence of depositors and the stability of the economic situation (Ulrich, 2012).

However, we should note certain shortcomings and difficulties that may face any investor. Despite the fact that the government and business representatives perfectly understand the need to raise funds for the rapid development of economy and business, in fact the investing in Russia is associated with the relatively high risks and legal barriers. Not all areas are sufficiently open to investment and not all investors are protected by law from the loss of funds. Therefore, if the investment into Russian business is very important for an investor, he 
should pay attention to the business and economy areas, which, in turn, are interested in attracting funds and thus provide assistance to investors.

According to surveys and sociological research, domestic and foreign investors indicate business environment in Russia as insufficiently supportive; Russia ranks $120^{\text {th }}$ in the world in terms of agility and ease starting and doing new business, bureaucracy, corruption, transportation problems and other equally important factors (Neusypin, 2009; Pishchulin, 2011; Ulrich, 2012).

Currently, in many industries and business areas there is a great lack of investments. Especially this concerns new projects and developments that are related to the field of venture investment. In the future, this situation can have a negative impact on the overall economic development of the country, as the use of outdated technology leads to a decrease in performance indicators, while the purchase of developments and new technologies from Western companies is quite expensive and unpromising business.

Despite the problems and the lack of experience, the country's economy still develops and the government takes measures to attract domestic and foreign capital. In order to attract more funds, customs control and administration procedures are simplified, the approaches to the design and development of new projects are improved, a network of business incubators is created and the procedure of connecting new companies to engineering and communication lines and power grids is simplified, the institution of regional authorized representatives on investments is established, and new laws and programs are developed and adopted.

The advantages of investing into the Russian economy, as well as public and private enterprises include:

- Rapid development of new business projects, firms, manufacturing companies, and as a consequence, a good return on investment;

- Possibility to acquire shares and other securities at competitive prices, since this market is still in a relatively quiescent state;

- Support at the legislative level; perhaps not everything is perfect so far, but the government works toward improvements, offering and passing bills and programs to attract investments into the Russian economy;

- Reasonably good information support and advisory services regarding concerned industry sectors;

- Increasing a number of various funds, mutual funds, and similar structures to help investors to choose the scope and invest in challenging investment projects, and to offer equity participation in the different categories of investment portfolios (Invest funds Information Resourse: Project of the Cbonds.ru Information Agency; Jaremenko, 2014; Fadeev, 2014).

Thus, on the one hand, investing in Russia is subject to certain risks, and on the other hand, it is attractive precisely because of relative calm in the financial market, sustainable development of economy and not too large number of foreign investors. Work on the reduction of risks and legal support is ongoing, and in the near future, those who invested and invest in securities, shares and other investments in the territory of the Russian Federation will become the owners of profitable portfolios or get a decent return on their investments.

Like any other field, investing is influenced by events, news, as well as preferences of various groups of investors.

In turn, preferences are influenced by a variety of factors, including amount of available money to invest, current rate of return, visible risks, perspective, the situation in a particular area of the economy, the adoption of new laws, government support, advertising, value of the shares, stocks, participation units, and so on.

Many types of investments in the Russian Federation have a low profitability, especially in comparison with inflation, whereas those types that bring good profits tend to carry a high risk that makes them not too attractive among individuals. Foreign investors primarily focus on legislative support and the degree of risk of a particular investment, while in most cases amount of funds is not too important, since they are not limited in financial assists.

Due to such difference in the selection criteria and approach, domestic and foreign investors prefer different areas for investments, though some types of investments show strong interest in both groups.

In Russia, there are quite many sustainable and well-growing companies, whose shares are unlikely to fall in price in the short term. Naturally, in most cases these are oil, gas production and processing companies and related industries. Shareholders of such companies receive relatively small dividends, though fairly stable, and the value of such securities has been steadily increasing in price. Until new forms of energy are developed, the interest in such companies will not weaken; therefore the investments in this area are very popular. 
Well-known companies and productions from other economy areas also issue shares, and though the interest in them is much smaller, they are in demand by many domestic mutual funds and private investors (Semenov, 2007; Mikhailov, 2006).

Commercial and industrial real estate, housing and communal services are in constant demand and, as a result, bring good revenue in the form of regular income from the rental and sale due to the continuous growth in their market value. However, such investments into the Russian real estate require from the investors sufficiently large initial amount of funds to be invested or good credit conditions.

Thus, investment into residential real estate or construction is limited by purchasing power of private investors.

Commercial real estate is in a stable demand, though many legal entities and small businesses prefer to rent space rather than buy it, because of their limited financial resources and uncertainty about the future.

Mutual funds and Forex Currency Exchange, popularized in the media, cause most investors opposite responses. Some are happy with the investment results into these instruments, while others, when received the first negative experience, respond very negatively. However, as always, the truth is somewhere in between. Western investors have the experience, knowledge and in most cases, having overcome a few setbacks, developed a personal strategy for investing policy (Goncharenko, 2002).

Forex trading is another popular type of financial investment for many investors in Russia. Comments about this kind of investment are most diverse, ranging from extremely negative to positive, and even enthusiastic. Such dispersion in opinions is quite intriguing, and considering the fact that the account opening rules are very simple, many investors are ready to invest at least a little money and find out how it works.

Investments into trading on the foreign exchange market are popular among both Russian and foreign investors. Latters prefer to invest in Forex trading through the firms operating in their home countries, as legal support there is much stronger and is based on a statutory basis.

Bank deposit programs are other relatively popular type of investment. However, the profitability of this type of investment is a big question as the interests offered by Russian banks barely cover the losses from inflation. Such investment is more suitable for conservation of the savings rather than for their multiplication. Yet many investors continue to use this method to save at least part of their capital. Naturally, foreign investors do not use this type of investment because of its low profitability.

Impersonal metal accounts are more progressive way to save money. According to the agreement, the investor acquires a certain amount of gold or other precious metals, which is subsequently stored in the bank, while the investor receives interest according to the increase in the market value of the metal. Thus, the profitability of such investments is directly proportional to the increase in metal prices on world markets.

Venture capital investment into the Russian IT-sphere is becoming the most promising sphere. This trend has recently made significant progress, and therefore the venture capital market has the highest growth rate among all other markets. Just in 2012 the total amount of investment into the new projects and developments of the Russian IT-sphere amounted to about 450 billion dollars, and this, of course, is not the limit, since the rate of the process development is increasingly growing. Consequently, the total number of investors, as well as specializations in this area is increasing rapidly (Goncharenko, 2008).

The history of venture capital investments in different countries shows how investing in new developments can become the strongest engine in economy growth at quite small initial investments. Contemporary venture funds are functioning according to the " $3 \mathrm{H}$ " formula: high risk - high tech (high technology) - high life (good living standard). Indeed, it is this approach that characterizes the investments into the field of new technologies.

The main idea behind the venture investments is to provide support of the specific projects at various stages of their formation and development for a bonus paid in the form of a relevant number of shares or stake in the new business project. Thus, private investments give rise to new pilot projects, gradually promoting the development of not only the economy, but also science; consequently, investors get very good profit.

The realities of venture capital investment involve a rather high risk and a long term of illiquidity. At that, in most cases the investment takes place directly into the companies' share capital, whereas profit comes from the sale of shares in the total capital or shares received in exchange for investment. Naturally, repayment and acquisition of income becomes possible only after the project succession. That is why the venture capital investments into the Russian projects are related to high risk investments; the ideas, underlying in those or other pilot projects, not always hit the jackpot and achieve considerable success. 
Most often, the investment recipients are venture capital firms, teams or even individuals, engaged in pilot projects in the field of new technologies. These projects can be invested by the funds, which specialize in this type of investment, as well as various intermediaries and private individuals, who have relevant information and capital. Interestingly, that in the field of venture capital investment one uses the classification of project development stages (or directly projects), which gives a rough understanding of the degree of risk for investments. It looks as follows.

1. Start or "seed" (in other words, sowing campaign). This stage is characterized by the availability of certain idea, which needs conducting market research or scientific study, creating the first samples, and developing a business plan. Preliminary positive evaluation of such project will attract investments, which in turn will be used to develop further the product or service, build a team and carry out other necessary activities. At this stage the risk is maximal.

2. Start-up. Start-up is a newly established company, which has already completed the development of the final product and conducted the related market research. In most cases start-ups have no commercial history, though they have a business plan, team, managerial developments and are completely ready for operation. At this stage the risk is also maximal.

3. Growth stage (early-stage). The project is already operating, producing the finished product. The next step is the market offtake and distribution of goods. At this stage, start-up companies quite often do not have enough funds for the development, further research, advertising, and other expenditure, necessary for further advancement. This stage is characterized by risk reduction.

4. Expansion of production and spheres of influence (expansion). This stage is characterized by increased sales and, consequently, getting profit. Though, even this stage often requires additional inflow of funds to expand production, increase circulation, or develop new products. This stage is characterized by even greater risk reduction.

The first three stages are attributed to the early stages, which have the highest degree of risk, while the fourth stage of "expansion" is considered more stable and productive step of development; here the risk is not high, whereas the returns are quite tangible.

Most domestic and foreign private investors, as well as investment funds, in order to reduce the risk, prefer to invest in companies, which are at the fourth stage of "expansion". Projects under "seed" and "start-up" stages have a maximum degree of risk, and therefore do not attract the interest among investors, though in some cases they are supported by the so-called "business angels" and venture capital funds.

The areas of venture capitalists' interest include not only IT-technologies, but also pharmaceuticals, medicine, construction and similar areas of the Russian economy. Such preferences are not accidental, since in these areas the degree of risk is by an order of magnitude smaller than that in the field of information technology.

However, for the further development and fledging, start-up Russian projects require a lot more money than can be provided de facto. Currently, in Russia there is not a single professional venture capital fund, as well as there is no legislation governing the operations of such fund. Therefore, the majority of these funds are registered in offshore zones. Emergence of funds managed by Internet entrepreneurs is a tendency of recent time.

Lack in amount of risk capital creates good conditions for foreign investors, though for Russia such situation is rather disadvantage. Domestic developments must be supported by means of Russian investors and venture capital funds, and only such approach will ensure normal development and fledging of IT-sphere, as well as other equally relevant areas.

In practice, however, the combined venture capital investments are the most common form, where part of the funds is invested into the share capital, while the other part is provided in the form of investment loan.

Usually venture investor does not seek to acquire a controlling stake interest in the company (at least, during the initial investment). And this is its radical difference from the "strategic investor" or "partner". Often, the latter initially wants to establish control over the company, which is of his interest for one reason or another.

The purpose of the venture capitalist is different. Acquiring a stake or a share, less than a controlling stake, the investor expects that the company's management will use his money as financial leverage in order to provide a more rapid growth and development of their business. Neither the investor, nor his representatives do not take any other risks (technical, market, managerial, price and so on), except of financial risk. All of these risks bear the company and its managers. In this case, another preference of the venture investor is belonging of a controlling stake to company managers. Having controlling stake, they retain all the incentives for active 
participation in business development. If the company succeeds during the period, when it affiliates venture investor as co-owner and partner, i.e. if for 5-7 years its cost increases by several times as compared to the initial cost prior to investment, the risks of both parties are justified and everyone gets adequate remuneration. If the company does not meet the expectations of the venture capitalist, he may completely lose his money (in the case where a company files for bankruptcy), or at best, return the investment without receiving any profit. Both the second and the third options are considered failures. Profit of venture capitalist arises only when within 5-7 years after the investment he will be able to sell his stake at a price several times higher than the initial investment. Therefore, venture investors are not interested in the distribution of profits in form of dividends, while preferring to reinvest all the profits into the business.

The future profitability of the financial transaction depends primarily on the selection of assets for investment, the time of the transaction, the investment horizon and other factors, forming the investment strategy.

Investment strategy is preceded by market analysis. One cannot ignore the fact that the investment in the domestic stock market is a multifaceted process.

For any investor, when choosing a facility or areas of investment, there are two the most important criteria: profitability and risk. Investments into the Russian economy and domestic financial instruments in most cases are quite risky because of inadequate legislation and other well-known factors. Any investment project may fail because of deficiencies in manufacturing technology, materials, resources, human factors, changes in the political situation, the adoption of new laws, etc. Thus, risk management even at an early stage of planning investments into Russian enterprises and companies is necessary for obtaining a successful result (Goncharenko et al., 2009; Akulinin, 2009; Galanov, 2010; Belotelova, 2012).

The concept of investment risk reflects the probability of occurrence of situations leading to a loss of profit and the total amount of the investment. Thus one should take into account all possible risks that may occur during the whole time of investment (Scott \& Storper, 2003; Simmi, 2003; Asheim, 2007).

Forecasting and subsequent management of investment risks requires firstly taking into account the possible situations and developing solutions for the diversification of the total amount of investment to reduce qualitatively and quantitatively different types of risk.

The following risk management programs are the most effective:

1. Risk reduction is the most successful program, known to each investor. It is based on the distribution (diversification) of funds to several projects or making investment into radically different spheres of activity and businesses. In the most cases, reducing the risk of investing in Russia involves the diversification of the total amount of funds between small projects or the creation of the investor's portfolio with diverse investments. It is difficult to overcome the failure and losses on investments into one big project, while the loss in a single small investment is practically invisible against the background of positive results from other investments.

2. Risk transfer. This means insurance against risk, i.e. buying and selling risk. Not all investments can be insured. If the risk is high, as for example, in venture investment, the insurance company may refuse such a transaction; this can be clearly understood.

3. Risk assessment. This risk program suggests that the investor understands and accepts the possibility of occurring risky situations during the investment and is ready to recoup losses from his own resources. When working with such a program, one must take into account the likelihood of such a situation and the maximum amount of losses. If such situations are rare and losses are not widespread, than a special financial reserve should be provided to cover possible losses. This solution will allow one not to use or reduce the amount of working capital, because in the realities of our economy decrease in working capital is fraught with serious problems (Stepanov, 2014; Stepanov, 2013; Christopherson \& Clark, 2007; Cooke et al., 2011; Cooke et al., 2007; Spier, 1970; Risbøl et al., 2003).

In some cases risk assessment leads consequently to risk aversion. In itself, this solution is good, but when considering the financial and economic processes and relationships, risk aversion can result in stagnation of business, loss of competitiveness and other similar problems.

\section{Conclusions}

Diversification, a rational attitude to risks, forecasting and insurance provide all together the best solutions for any kind of investment in the Russian Federation. Investing in Russia is always subject to different risks. Thus, solutions to possible problems should be reflected in the so-called risk list. This document should be developed 
directly before investing and should include all risks most common to a certain scope of investment. Also, it is necessary to assess potential losses and provide ways to minimize them.

Any investor, regardless of his experience, should understand the danger of investment risks, anticipate such situations and develop possible solutions to the problems. In fact, both business leaders and private investors are often struggling against the results and hastily looking for ways to reduce the losses incurred that is fundamentally wrong practice.

Other types of investments, such as investing into the development of own business, new projects, and scientific research are not too popular and seem challenging just to a limited group of entrepreneurs.

\section{References}

Akulinin, F. (2009). Investment support issues of innovative economic development. Almanac of Contemporary Science and Education, 3, 8-10.

Asheim, B. (2007). Regional systems of innovation and differentiated knowledge bases: an analytical theoretical framework.

Belotelova, Zh. (2012). The problems of the banking system in the post-crisis conditions. Bulletin of the Moscow State University on Instrument Engineering and Informatics. Socio-economic sciences, 39, 118-121.

Christopherson, S., \& Clark, J. (2007). Power in firm networks: What it means for regional innovation systems. Regional Studies, 41(9), 1223-1236.

Cooke, P., Laurentis, C., Tödtling, F., \& Trippl, M. (2007). Regional knowledge economies. Markets, clusters and innovation. Cheltenham. Edward Elgar.

Cooke, Ph., Asheim, B., Boschoma, R., Martin, R., Schwartz, D., \& Todtling, F. (2011). Handbook of regional innovation and growth. London. Edward Elgar.

Fadeeva, O. (2014). Professional and qualimetric culture of economist. Proceedings of the International Scientific and Practical Conference on the topical issues of contemporary Russian society. Moscow.

Galanov, V. (2010). Securities market. RIOR: INFRA-M. Moscow.

Goncharenko, L. (2002). Entrepreneurial risks. Finance and Credit, 11, 10-14.

Goncharenko, L., \& Filin, S. (2008). Risk management. Moscow.

Goncharenko, L., Keschyan, V., \& Akulinin, F. (2009). Issues on ensuring state economic security. Transportation Business in Russia, 9, 76-78.

Invest funds information resource. Project of the Cbonds.ru. information agency. Retrieved December 5, 2014, from http://pif.investfunds.ru.

Kolupaev, R. (2014). A model for regional management of the investment attractiveness of industry. Life Science Journal, 11(8), 86-89.

Kolupaev, R. (2014). Tools for creating a safe investment climate in Russia. Scientific Review, Economics and Law, 1(1), 12-15.

Maloletko, A., Kaurova, O., Grunin, A., Zotova, A., Kourbanov, T., \& Revyakina, T. (2014). The management of regional tax potential. Life Science Journal, 11(12), 412-414.

Mikhailova, T. (2006). Regulation and self-regulation of entrepreneurial activity (PhD thesis). Moscow.

Neusypin, K. (2009). Investigation of the management systems. Moscow.

Pishchulin, V. (2011). Russian power economy expects innovations. Energy: economy, technology, and ecology, 6, 63-69.

Pishchulin, V., \& Rogachev, M. (2013). Implementation of the economic rights of citizens in contemporary conditions. Proceedings of the First International Symposium on contemporary aspects of fundamental science. Moscow.

Risbøl, O., Risan, T, Bjørnstad, R., Fretheim, S., Håkon, B., \& Rygh, E. (2003). Cultural heritage in Gråfjell Regionfelt Eastern Norway Amot in Uedmark. Oslo. Archaeological registration.

Scott, A., \& Storper, M. (2003). Regions, globalization, development. Regional Studies, 37(6\&7), 579-593.

Semenov, A. (2007). Venture investment in Russia. Vershina. Moscow. 
Simmi, J. (2003). Innovation and urban regions as national and international nodes for the transfer and sharing of knowledge. Regional Studies, 7(6\&7), 607-620.

Spier, R. (1970). Surveying and mapping: A manual of simplified techniques. New York. Holt, Rinehart and Winston.

Stepanov, A. (2014). Objective laws of the performance management of regional socio-economic development. Proceedings of the International Extramural Scientific-Practical Conference on internal and external drivers of economic growth. Moscow.

Stepanov, A., \& Tarasenko, S. (2013). Social capital of innovation and model for its implementation in the economy. Bulletin of the Moscow State Academy of Business Administration, Economy, 2(22), 105-113.

Ulrich, I. (2011). Experience in implementing measures to overcome the effects of the global financial crisis in the social sphere (evidence from the social policy in the USA during the global financial crisis of 1929-1933). Economy and Society: Modern Development Models, 1, 166-175.

Ulrich, I. (2012a). Effectiveness analysis of the Russian government activities to overcome the global financial crisis in the social sphere. Economy and Society: Modern Development Models, 3, 265-273.

Ulrich, I. (2012b). Peculiarities of the innovation process in the petroleum refining industry in the Russian Federation. Transportation business in Russia, 4, 97-100.

Yaremenko, N. (2014). Tendency in the development of mortgage lending in Russia. The World of Science, Culture and Education, 2(45), 416-423.

\section{Copyrights}

Copyright for this article is retained by the author(s), with first publication rights granted to the journal.

This is an open-access article distributed under the terms and conditions of the Creative Commons Attribution license (http://creativecommons.org/licenses/by/3.0/). 